\title{
Mechanical activation in utilising milling byproducts: a way to improve effectiveness
}

\author{
Nataliya Lesnikova ${ }^{1, *}$, Olga Chugunova $^{1}$, Valentina Lapina $^{1}$, Tatiana Kotova ${ }^{1,2}$, and \\ Ekaterina Pastushkova ${ }^{1}$ \\ ${ }^{1}$ Ural State University of Economics, 8 Marta/Narodnoy Voli St. 62/45, 620144 Ekaterinburg, Russia \\ ${ }^{2}$ Kemerovo State Medical University, Voroshilova st., 22a, 650056 Kemerovo, Russia
}

\begin{abstract}
The study focuses on obtaining the finely ground wheat germ flour mix by employing dry mechanical activation. During the study, wheat germ is ground using DESI-11 disintegrator and mechanically activated in PM-10 centrifugal mill with the rotor speed of $1050 \mathrm{rpm}$. According to the study findings, the finely ground wheat germ flour mix obtained by dry mechanical activation possesses increased bulk density and improved water absorption capacity when compared to the product obtained from wheat germ without mechanical activation applied. The average particle size is reduced from $114 \mu \mathrm{m}$ to $52 \mu \mathrm{m}$. The study findings indicate that obtaining the finely ground wheat germ flour mix by dry mechanical activation prevents the occurrence of the caking effect as well as improves the quality of baked products.
\end{abstract}

\section{Introduction}

All over the world producers are striving for waste-free manufacturing processes by employing sustainable practices during the entire production processes. Nevertheless, byproduct utilisation is a challenging prospect for many process industries. Basically, grain processing produces such byproducts as wheat germ and barn which can be successfully utilised.

Considering both the excellent chemical composition of wheat germ and the fact that wheat grains are carefully screened before milling to ensure finished products of high quality, wheat germ is currently regarded as being a high value food additive for bread and pastry industry [1-3].

To ensure that wheat germ flour mix improves the nutritional value of finished foods, it is advisable to choose natural ingredients as they are a concentrated source of essential nutrients which are absorbed easier by the body [4].

To properly enhance the nutritional value of processed foods, the chemical composition of the finely ground wheat germ flour mix includes wheat germ, chicory inulin, and soy lecithin. Inulin is a water-soluble prebiotic fiber that supports digestive health. The use of inulin offers a number of benefits. When inulin absorbs water, it creates a gelatinous mass. Inulin is indigestible by the human enzymes and helps balance the good bacteria and support gut health [5].

\footnotetext{
* Corresponding author: lesnina@usue.ru
} 
Lecithin represents the most common natural phospholipids which are vital constituents of biological membranes and building blocks for cells as well as nerve tissues. Soy lecithin contains a significant amount of minerals (magnesium, potassium, calcium, iron, etc.), as well as organic chemical compounds such as tocopherols (vitamin E) and $\beta$-Sitosterols (provitamin D) [6].

The aim of the present study is to calculate the optimal ratio of ingredients for the finely ground wheat germ flour mix to utilise one of the byproducts of grain processing, namely wheat germ. The study is carried out by applying mathematical modelling and comparative analysis.

\section{Materials and Methods}

The objects of the study are:

- defatted wheat germ power which is the main byproduct in the oil extraction process. For the oil extraction process, a novel technology of extracting oil from wheat germ by applying cold pressing is used.

- chicory inulin powder. To obtain chicory inulin powder, first, chicory was soaked in hot water, then purified, and finally, spray-dried.

- soy lecithin powder "Lecigran 1000P";

- wheat germ flour mixes. Two mixes were compared, the first one was treated with mechanical activation and the other was not.

- During the study, both conventional and new methods for examining raw materials and semi-finished products were applied.

The moisture content of the wheat germ flour mix was calculated in accordance with GOST 9404-88 "Flour and bran. Method of moisture content determination" (GOST is the set of the technical standards maintained by the Federal Agency on Technical Regulating and Metrology). To determine the moisture content, the wheat germ flour mix was dehydrated in an air-thermal cabinet at a fixed temperature and for a fixed period of time.

The protein content of the wheat germ flour mix was determined according to the Kjeldahl method. To begin with, the sample was digested with sulfuric acid to convert into ammonium sulfate. When converted into ammonia, the sample was then distilled into an acid solution. Finally, titration with a sulfuric acid solution was performed and the nitrogen content was calculated.

The fat content of the wheat germ flour mix was determined by, first, the extraction of crude fat using a solvent. Then, the solvent was removed, and the extracted fat was dried and weighed.

The starch content was measured by applying a polarimetric method; it means that the starch was dissolved in a hot calcium chloride solution.

To determine the carbohydrate content of the wheat germ flour mix, sugars were converted into trimethylsilyl derivatives to be then analysed with the gas chromatography technique.

The dietary fiber content was determined using the enzymatic method. The sample was treated with enzymes to imitate the digestive process that happens in the human body. The hydrolysis reaction was carried out with protein and starch removed.

Column chromatography was applied to determine the content of fat-soluble vitamins A and $\mathrm{E}$ as well as the content of beta-carotene in the sample. The method is based on the spectrophotometric determination of the vitamin content in the solution obtained after its extraction from the sample with an organic solvent and separated from the other compounds using alumina. 
The determination of vitamin B content was carried out by employing fluorometric method, which was implemented in the following steps. The first step was to apply acid and enzymatic hydrolysis to obtain the bound forms of B-group vitamins. Then, the hydrolysate was purified by column chromatography. The next step included oxidation of thiamine in an alkaline solution, extraction of thiochrome. Finally, the fluorescence intensity of thiochrome was measured using a fluorometer.

The vitamin PP content was determined by a colorimetric analysis. First, hydrolysis was carried out to obtain the bound forms of niacin, the hydrolysate was purified and glutaconic aldehyde derivative was obtained. Finally, colorimetric analysis of the mass fraction of 400-425 nm was applied and compared to a standard solution.

In accordance with GOST 27493-87 "Flour and bran. Method for determining acidity by using thin flour dough", the acidity of the sample was determined by titration with sodium hydroxide. All acid-reacting substances of the sample were titrated.

The particle size distribution and the average particle size were determined using GIU-1 granulometer, which is a device used to analyse the particle size.

To determine the bulk density of the wheat germ flour mix, a PT-SV100 Scott Volumeter was used.

The water absorption capacity of flour is the amount of water absorbed by flour to achieve the expected consistency and create a quality product and measured in (\%) to $100 \mathrm{~g}$ of flour [7-9].

\section{The results and discussion}

To develop a recipe for the wheat germ flour mix of high nutritional value, mathematical modelling was carried out. The ratio of the ingredients was calculated using the method of the sequential experiment planning. When calculating the ratio, the main focus was on the properties of the ingredients $[10,11]$.

The ratio of the ingredients is shown in Table 1.

Table 1. The ratio of the wheat germ flour mix ingredients.

\begin{tabular}{|c|c|}
\hline Ingredient & Content, mass fraction \% \\
\hline Wheat germ powder & 65 \\
\hline Chicory inulin & 25 \\
\hline Soy lecithin & 10 \\
\hline
\end{tabular}

The chemical composition of the wheat germ flour mix is given in Table 2.

Table 2. The chemical composition of the wheat germ flour mix.

\begin{tabular}{|c|c|}
\hline Constituents & Amount (value per 100g) \\
\hline Water & $6.2 \pm 0.1$ \\
\hline Protein & $33.9 \pm 1.6$ \\
\hline Fat & $7.9 \pm 0.4$ \\
\hline Monosaccharides and disaccharides & $32.7 \pm 1.1$ \\
\hline Dietary fiber & $17.2 \pm 0.2$ \\
\hline Ash & $16.3 \pm 0.5$ \\
\hline
\end{tabular}


Table 2. Continued

\begin{tabular}{|c|c|}
\hline \multicolumn{2}{|l|}{ Vitamins: } \\
\hline Vitamin A & $8.0 \pm 0.1$ \\
\hline Beta-carotene & $0.05 \pm 0.01$ \\
\hline Vitamin $B_{1}$ & $0.6 \pm 0.1$ \\
\hline Vitamin $B_{2}$ & $0.87 \pm 0.02$ \\
\hline Vitamin E & $9.9 \pm 0.1$ \\
\hline Vitamin PP & $11.5 \pm 0.5$ \\
\hline Vitamin $\mathrm{B}_{3}$ & $4.1 \pm 0.2$ \\
\hline \multicolumn{2}{|l|}{ Minerals: } \\
\hline Potassium & $783.0 \pm 21.0$ \\
\hline Calcium & $29.0 \pm 0.5$ \\
\hline Magnesium & $178.0 \pm 5.1$ \\
\hline Sodium & $5.0 \pm 0.2$ \\
\hline Phosphorus & $1075.0 \pm 43.0$ \\
\hline Iron & $4.4 \pm 0.1$ \\
\hline
\end{tabular}

To obtain the finely ground wheat germ flour mix, the method of mechanical activation was considered. When natural polymers are subjected to mechanical activation, they change their structure, chemical properties, and their energy state because of the application of significant mechanical forces. The process of mechanical activation is carried out in a highspeed and repetitive mode $[12,13]$.

For the present study, the wheat germ was ground using DESI-11 disintegrator. This disintegrator is designed for grinding loose, powder and granular materials to powders. The mechanical activation was carried out with the help of PM-10 centrifugal mill with the rotor speed of $1050 \mathrm{rpm}$. After applying mechanical activation, a light yellow powder with a particle size of 0.35-0.68 $\mu \mathrm{m}$ was obtained. We used AACC 55-40.01 method to determine the particle size by a laser light scattering device [14].

The particle size distribution is one of the important physical properties of flour that influences its application. Table 3 shows the particle size distribution in both samples of the wheat germ flour mix, with and without mechanical activation.

Table 3. The particle size distribution.

\begin{tabular}{|c|c|c|}
\hline Particle size, $\boldsymbol{\mu m}$ & $\begin{array}{c}\text { The particle size distribution: } \\
\text { the mix without mechanical } \\
\text { activation, \% }\end{array}$ & $\begin{array}{c}\text { The particle size distribution: } \\
\text { the mechanically activated mix, } \\
\mathbf{\%}\end{array}$ \\
\hline$<20$ & - & $2.5 \pm 0.5$ \\
\hline $20-40$ & - & $8.5 \pm 0.5$ \\
\hline $40-60$ & $6.0 \pm 0.5$ & $76.0 \pm 5$ \\
\hline $60-80$ & $5.5 \pm 0.5$ & $13.0 \pm 3$ \\
\hline $80-100$ & $35.0 \pm 5$ & - \\
\hline $100-130$ & $38.0 \pm 4$ & - \\
\hline $130-160$ & $12.0 \pm 2$ & - \\
\hline $160-190$ & $3.5 \pm 0.5$ & - \\
\hline
\end{tabular}

As illustrated in Table 3, when the wheat germ flour mix is prepared without mechanical activation, the particle size ranges from 40 to 190 microns, whereas the particle 
size of the mechanically activated wheat germ flour mix is up to 80 microns. It is important to emphasise that particles with the size range of 40-60 microns account for 76 per cent of the total.

To determine the particle size distribution in both the mechanically activated wheat germ flour mix and the wheat germ flour mix without mechanical activation, we applied the method of laser light scattering (in accordance with AACC Method 55-40.01, Particle Size of Wheat Flour by Laser Instrument), which is internationally used for this analyses in the grain industry. Together with the scanning electron microscopy, this method allowed us to achieve greater accuracy. The distribution of particles by fractions is shown in Figure 1.

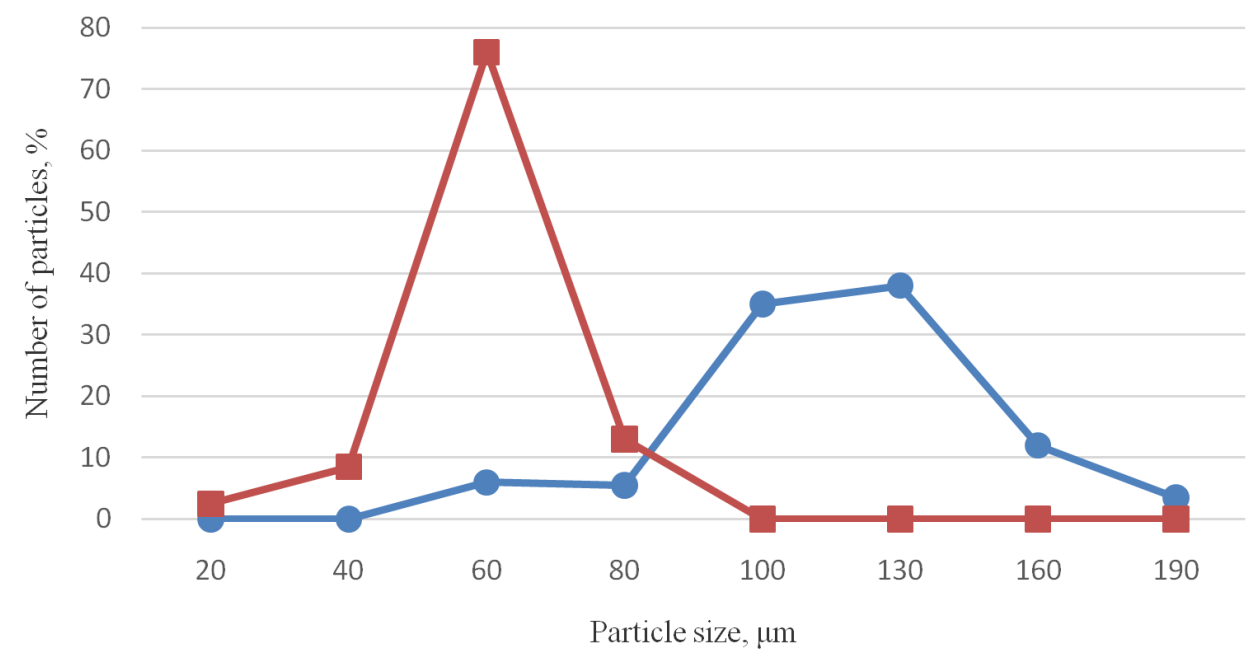

without mechanical activation

- mechanically activated

Fig. 1. The distribution of particles by fractions.

The study findings indicate good convergence of the particle size distribution in the mechanically activated wheat germ flour mix. And when the mechanically activated wheat germ flour mix is used, a more uniform structure is obtained which is important for the baking industry [15].

The physicochemical and functional properties of the wheat germ flour mix are shown in Table 4.

Table 4. The physicochemical and functional properties of the wheat germ flour mix.

\begin{tabular}{|c|c|c|}
\hline \multirow{2}{*}{ Property } & \multicolumn{2}{|c|}{ Wheat germ flour mix } \\
\cline { 2 - 3 } & $\begin{array}{c}\text { without mechanical } \\
\text { activation }\end{array}$ & mechanically activated \\
\hline Moisture content, \% & $10.8 \pm 0.3$ & $10.5 \pm 0.2$ \\
\hline Acidity, degree & $4.2 \pm 0.1$ & $5.8 \pm 0.1$ \\
\hline $\begin{array}{c}\text { Average equivalent particle } \\
\text { diameter, deq, } \mu \mathrm{m}\end{array}$ & $114 \pm 2.5$ & $52 \pm 0.8$ \\
\hline Bulk density, $\mathrm{kg} / \mathrm{m}^{3}$ & $385 \pm 15$ & $760 \pm 32$ \\
\hline $\begin{array}{c}\text { Water absorption capacity, } \\
\%\end{array}$ & $55 \pm 5$ & $72 \pm 4$ \\
\hline
\end{tabular}

As illustrated in Table 4, the mechanically activated wheat germ flour mix demonstrates higher bulk density and water absorption capacity when compared to the mix without 
mechanical activation. The average equivalent particle diameter of the mechanically activated wheat germ flour mix is $52 \mu \mathrm{m}$ which is almost twice as low as the average equivalent particle diameter of the wheat germ flour mix without mechanical activation.

The findings of the study suggest that the finely ground wheat germ flour mix will demonstrate storage stability and can be used to produce a consistent finished product.

\section{Conclusions}

The present study was designed to explore the way to utilise wheat germ as one of the grain processing byproducts. During the study, the positive impact of mechanical activation on the wheat germ flour mix has been confirmed. Overall, the study findings offer a solution to the matter of the rational use of the grain processing byproducts as well as provide a way to improve the nutritional value of finished products.

\section{References}

1. V.V. Pushmina, I.N. Pushmina, G.G. Pervyshina, L.M. Zakharova, Izvestiya FEFU. Economics and Management, 3 (2017)

2. S.S. Kuzmina, L.A. Kozubaeva, D.N. Protopopov, Polzunovsky Vestnik, 2 (2017)

3. N.A. Lesnikova, T.V. Kotova, XXI century: results of the past and problems of the present plus, 3(51) (2020)

4. V.Ya. Chernykh, A.S. Maksimov, O. A. Godunov, Bread baking in Russia, 1 (2019)

5. M.V. Chistova, Food Industry, 7 (2012)

6. T.A. Ershova, S.D. Bozhko, A.N. Chernyshova, I.O. Vakhobova, Food and processing industries: Technologies. APK-Healthy Food Products, 3 (2019)

7. S.P. Merenkova, A.A. Lukin, Scientific journal of NRU ITMO. Series "Food Production: Processes and Equipment", 3 (2015)

8. M.B. Rebezov, N.L. Naumova, M. Yu. Kofanova, Food production techniques and technology, 1(24) (2012)

9. N.S. Rodionova, E. S. Popov; E. A. Pozhidaeva, N. N. Popova, T. N. Kolesnikova, E. S. Pevtsova, K. V. Bortnikova, Storage and Processing of Agricultural Raw Materials, 12 (2017)

10. I.A. Tyurina, E.V. Nevskaya, A.E. Borisova, I.P. Peshkina, All About Meat, 55 (2020)

11. E.I. Ponomareva, N.N. Alekhina, I.A. Bakaeva, Nutrition Issues, 85(2) (2016)

12. L.Yu. Lavrova, Food Industry, 1 (2016)

13. V.E. Radjabova, Science and Education Today, 1 (2018)

14. N.V. Naumenko, I. Yu. Potoroko, I.V. Kalinina, A.V. Malinin, A.V. Tsaturov, Vestnik VSUIT, 81(2) (2019)

15. I.B. Isabaev, T.I. Atamuratova, Food production techniques and technology, 48(2) (2018) 